\title{
JOGANDO COM O NARRADOR: ESTRATÉGIAS NARRATIVAS NA PRODUÇÃO DE TEXTOS EM AMBIENTES ESCOLARES INFORMATIZADOS
}

\section{Maria Cristina Palma Mungioli}

\section{RESUMO}

Este relato apresenta a análise de algumas estratégias narrativas empregadas por alunos de $5^{\mathrm{a}}$. e $6^{\mathrm{a}}$. séries do Ensino Fundamental na produção de textos em ambiente informatizado. O foco de atenção recai sobre as estratégias usadas pelo narrador na construção textual. As narrativas analisadas foram elaboradas por meio de um processador de textos e de imagens (Micromundos). A perspectiva de análise adotada considera tanto as pesquisas acerca da narrativa, entendida como forma de compreensão, representação e criação da realidade quanto questões relativas à dialogia e à interação verbal. Abordam-se também alguns aspectos referentes ao uso do computador em ambiente escolar. Discutem-se algumas das transformações ocorridas com a chegada do computador na sala de aula no que diz respeito ao relacionamento aluno-aluno, aluno-computador, aluno-professor e alunoconhecimento.

\section{PALAVRAS-CHAVE}

Narrativas; Estratégias narrativas; Pensamento narrativo; Dialogia; Aprendizagem em ambientes informatizados; Linguagem e cognição

\section{PLAYING WITH THE NARRATOR: COMPOSITION STRATEGIES IN LEARNING ON COMPUTER ENVIROMENT}

\begin{abstract}
This paper presents the analysis of narrative strategies used by students of Elementary School in texts composition in computers enviroment. The attention is aimed to the strategies used by the narrator in the text composition. The analyzed narratives were produced using a word and image processor (Microworlds). The analysis' perspective considers the narrative researches; that analyze them as a comprehension form, as a representation and as reality creation, it was also studied some questions related to dialogism and verbal interactions. Aspects of computer's use in the educational environment are also discussed. On this last perspective, some of the transformations concerning the relationship student-student, student-computer, student-teacher and student-knowledge were focused.
\end{abstract}

\section{KEYWORDS}

Narratives; Narrative strategies; Narrative thought; Narrative culture; Dialogism, Computer-based learnin; Language and cognition 


\section{INTRODUÇÃO} “(...) em nossa época a literatura se vem impregnando dessa antiga
ambição de representar a multiplicidade das relações em ato e
potencialidade.”

Calvino (1998, p.127)

Embora o termo hipertexto tenha sido cunhado recentemente, pode-se dizer que a estrutura hipertextual não é novidade em literatura. Histórias orientais, principalmente as árabes (As histórias das mil e uma noites, é a mais conhecida delas), apresentam histórias sem fim cujos motivos e personagens, à maneira de um hipertexto ${ }^{1}$ atual, remetem a outros textos e personagens. Encontram-se influências desse tipo organização discursiva no Decameron, de Boccacio, e nas Trecento Novelle, de Franco Sacchetti. No século XX, escritores como Cortázar e Borges criaram histórias com estruturas labirínticas. Ts’ui Pên , personagem do conto de Borges "El jardin de senderos que se bifurcan” (1942), compara o livro a um labirinto dizendo: "Me retiro a escribir um libro. Me retiro a construir um laberinto."

Entretanto, se esse tipo de narrativa não é novo, o estudo do texto narrativo tem apresentado transformações importantes ao longo do tempo. De Aristóteles até hoje, especialistas das mais diversas áreas têm se dedicado à análise de textos narrativos com a intenção de compreendê-los. Porém, podemos considerar que foi somente a partir dos trabalhos realizados por alguns pesquisadores soviéticos, conhecidos no ocidente como Formalistas Russos, que o estudo sistemático da narrativa começou a se delinear e serviu como uma espécie de linha divisória entre formas distintas de se estudar a narrativa.

De maneira resumida, em termos históricos, essas perspectivas representam dois grandes momentos. O primeiro deles caracteriza-se pelo estudo da narrativa enfatizando a interpretação, sendo a exegese a representação máxima desse período. No segundo momento, evidencia-se o estudo sistemático da narrativa do ponto de vista de suas estruturas. A publicação, em

\footnotetext{
${ }^{1}$ Com Ingedore Koch, Desevendando os segredos dos textos, p. 63, consideramos hipertexto “(...) uma escritura não-seqüencial e não-linear que se ramifica e permite ao leitor virtual o acessamento praticamente ilimitado de outros textos, a partir de escolhas locais e sucessivas em tempo real.” Além disso, a mesma autora afirma que as características interativas de natureza constitutiva de sua estruturação textual “ (...) faz[em] do leitor [do hipertexto], simultaneamente, um co-autor do texto, oferecendo-lhe a possibilidade de opção entre caminhos diversificados, de modo a permitir diferentes níveis de desenvolvimento e aprofundamento de um tema.”

${ }^{1}$ Essas estratégias definem-se por meio de mecanismos que o autor emprega ao construir seu texto e que envolvem em maior ou menor grau todos os elementos da narrativa (narrador, personagem, enredo, espaço, tempo). Esse conceito será explicado com mais detalhes no item 3 deste relato.
} 
1928, do livro "Morfologia do Conto", de Vladimir Propp, pode ser considerada o marco inicial desse período. Entretanto, somente trinta anos depois (data da publicação americana) essa obra irá influenciar o estruturalismo de Lévi-Strauss e inspirar não apenas "a análise dos mitos de Greimas como também o estudo dos contos de Bremond e o recorte mais literário de Barthes, Todorov, Genette.” (ADAM, 1994, p.5)

A interpretação deixa de ser a única via de análise do texto narrativo; surgem, então, as análises sobre as estruturas e os discursos narrativos.

Dando continuidade a essa segunda perspectiva, surgiram, nas últimas décadas, diversos trabalhos de pesquisa que associam a narrativa a formas elaboradas de pensamento e que a consideram responsável pelo processo de construção e representação do pensamento humano (BRITTON; PELLEGRINI, 1990; CHAFE, 1990; BRUNER, 1997, 1998, 2001; OLSON, 1990; OLSON; TORRANCE, 1995). Essas pesquisas colocam os estudos sobre narrativas na ordem do dia e re-significam seu valor cognitivo e social.

Numa tentativa de aliar as discussões acerca do uso do computador em ambiente escolar aos estudos da narrativa, nosso trabalho de pesquisa visou à análise das estratégias narrativas $^{2}$ empregadas por alunos de $5^{\mathrm{a}}$ e $6^{\mathrm{a}}$ séries do Ensino Fundamental na criação de textos narrativos com um processador de textos e de imagens, também foram objeto de observação as relações que se estabelecem entre professor-aluno, aluno-aluno e alunoconhecimento no laboratório de informática.

Buscando alternativas que levassem em conta as possibilidades de criação textual proporcionadas pela tecnologia computacional, desenvolvemos e executamos, juntamente com sete alunos de uma escola particular da cidade de São Paulo, um trabalho de produção textual que tinha como característica principal a elaboração de uma narrativa cujo enredo permitisse múltiplas possibilidades de desenvolvimento, às quais o leitor teria acesso resolvendo enigmas e desafios contidos na história. As narrativas elaboradas possuíam características hipertextuais em sua arquitetura, uma que vez aliavam textos, imagens e sons de maneira interativa, e, esteticamente, assemelhavam-se a jogos de videogame e de computador.

\footnotetext{
${ }^{2}$ Essas estratégias definem-se por meio de mecanismos que o autor emprega ao construir seu texto e que envolvem em maior ou menor grau todos os elementos da narrativa (narrador, personagem, enredo, espaço, tempo). Esse conceito será explicado com mais detalhes no item 3 deste relato.
} 
No presente relato, acrescentamos e atualizamos algumas análises do ponto de vista discursivo em relação à pesquisa de campo que deu origem a este estudo. ${ }^{3}$. O elemento da narrativa , objeto da atual análise, será o narrador, também serão discutidas, do ponto de vista discursivo, algumas estratégias por ele empregadas. É ainda nosso objetivo apresentar alguns aspectos referentes ao desenvolvimento do trabalho de produção de textos em laboratório de informática como ambiente pedagógico.

Os textos foram analisados à luz das contribuições de Bakhtin (2002, 1992), Eco (1986, 1997) e Charaudeau (2008) aos estudos da linguagem. Como primeira aproximação, destacamos algumas questões acerca da comunicação verbal sugeridas por Bakhtin (1992, p. 321) que nortearam nosso percurso de análise: "A quem se dirige o enunciado? Como o locutor (ou escritor) percebe e imagina seu destinatário? Qual é a força da influência deste sobre o enunciado?”^ Os trabalhos de Eco $(1986,1997)$ consideram que o autor, ao escrever, possui um horizonte implícito de expectativas em relação ao leitor de sua obra. Esse horizonte é predeterminado pelo texto que transmite orientações de leitura, de interpretação por meio do emprego de estratégias textuais.

Para a discussão de aspectos cognitivos referentes ao emprego das estratégias narrativas, baseamo-nos nas pesquisas de Bruner $(1997,1998,2001)$ e Chafe (1990) em que esses autores discutem o papel essencial da narrativa tanto para o desenvolvimento da cognição quanto para a constituição do ser humano. ${ }^{5}$ Alguns aspectos referentes ao processo de ensino-aprendizagem foram analisados levando em consideração os conceitos de mediação e de zona de desenvolvimento proximal desenvolvidos por Vygotsky (1991).

\footnotetext{
${ }^{3}$ Referimo-nos à pesquisa relatada em Maria Cristina P. Mungioli, Narrativas e computador: diálogos entre mundos reais e mundos possíveis. Em Narrativas e computador: criando mundos e experimentando realidades, analisamos as estratégias narrativas referentes a enredo e personagem. Também foram abordados assuntos referentes ao quadro teórico da pesquisa no artigo: Apontamentos para o estudo da narrativa.

${ }^{4}$ A partir dessas indagações M. Bakhtin, in Estética da criação verbal, p. 320, afirma: “(...) o enunciado, desde o seu início, elabora-se em função da eventual reação-resposta, a qual é o objetivo preciso de sua elaboração. (...) Os outros, para os quais meu pensamento se torna, pela primeira vez, um pensamento real (e , com isso, real para mim), não são ouvintes passivos mas participantes ativos da comunicação verbal. Logo de início, o locutor espera deles uma resposta, uma compreensão responsiva ativa. Todo enunciado se elabora como para ir ao encontro dessa resposta."

${ }^{5}$ J. Bruner, Atos de significação, p. 65, afirma que: (...) negociar e renegociar os significados por intermédio da interpretação narrativa é, segundo me parece, um dos corolários das conquistas do desenvolvimento humano, no sentido ontogenético, cultural e filogenético desta expressão.” W. Chafe, Some things that narratives tell us about the mind, in: Narrative Thought and Narrative Languag, p. 79, considera "narrativas como manifestações abertas da mente em ação: como janelas para ambos conteúdo da mente e operações em andamento.”
} 


\section{MÉTODOS}

\subsection{METODOLOGIA E OBJETIVOS DA PESQUISA}

Como objetivo principal de nossa pesquisa foi compreender as estratégias narrativas empregadas pelos alunos na produção de textos, bem como observar as relações que se estabeleciam entre professor-aluno, aluno-aluno, aluno-professor-conhecimento, adotamos a pesquisa qualitativa como forma de abordagem metodológica.

As peculiaridades da nossa investigação levaram-nos a optar pela limitação do universo de pesquisa a dez alunos e a definir como local de sua realização uma escola cujos alunos já conhecessem o software por nós escolhido e que permitisse a condução da pesquisa de maneira independente. O estudo adquiriu contornos de uma pesquisa-participante, pois, além das observações dos itens relacionados, orientamos os alunos sobre procedimentos do programa ou sobre aspectos da produção textual propriamente dita.

Os procedimentos adotados, em termos de análise e compreensão dos dados, remeteram a pesquisa ao chamado estudo de caso $^{6}$, uma vez que cada narrativa foi abordada com o intuito de estudar suas peculiaridades, inter-relacionando-as ao contexto escolar e sócio-cultural dos alunos participantes bem como agregando à análise dados presenciais que colhemos durante a pesquisa de campo. O passo seguinte foi correlacionar as semelhanças entre as narrativas e analisá-las como um conjunto de manifestações típicas do universo pesquisado.

A pesquisa de campo desenvolveu-se em 12 sessões semanais com 1h30min. de duração (perfazendo um total de 18 horas) com alunos de $5^{\mathrm{a}}$ e $6^{\mathrm{a}}$ séries do Ensino Fundamental com idade entre 10 e 12 anos. A definição da faixa etária e das séries participantes levou em conta que a maior ênfase do trabalho com narrativas se dá nessas duas séries do Ensino Fundamental. Um grupo de sete alunos (quatro da $5^{\mathrm{a}}$ série e três da $6^{\mathrm{a}}$ série) compareceu assiduamente às aulas e finalizou seus trabalhos.

\footnotetext{
${ }^{6}$ M. Lüdke \& M.E.D.A. André, Pesquisa em Educação: Abordagens Qualitativas, p. 17, afirmam que o estudo de caso caracteriza-se por permitir ao pesquisador a análise dos dados peculiares colhidos: " $O$ interesse, portanto, incide naquilo que ele (o caso) tem de único, de particular, mesmo que posteriormente venham a ficar evidentes certas semelhanças com outros casos ou situações.”
} 
As narrativas do corpus foram desenvolvidas usando o processador de textos e de imagens MICROMUNDOS (uma versão do LOGO-WRITER). Trata-se de um programa que dispõe de uma série de procedimentos e ferramentas mais “fáceis” de usar que os da versão Logo-Writer: a inclusão de uma barra de procedimentos e de uma "caixa de ferramentas" facilita o trabalho do aluno, que, assim, não mais precisa "ensinar" a tartaruga a mudar de página ou a utilizar a escrita em vez do traço. Esse programa possibilita o uso de letras coloridas, fundo de tela e desenhos e dispõe de um arquivo de cenários e figuras prontas. ${ }^{7}$

Mesmo os alunos que não haviam trabalhado com a linguagem LOGO apresentaram, logo no início do projeto, comentários favoráveis ao uso desse software, principalmente porque viam nele muitas semelhanças com o Word for Windows com o qual já estavam familiarizados e também pela facilidade que o Micromundos oferece para se trabalhar com cores, sons, desenhos.

\subsection{REALIZAÇÃO DA PESQUISA E CARACTERÍSTICAS DO CORPUS E DOS ALUNOS}

A pesquisa realizou-se em uma escola privada cuja clientela provinha da classe média e da classe média alta e estava localizada no bairro do Morumbi. Na época da realização da pesquisa, a escola tinha mais de vinte anos de existência e era considerada uma das precursoras no uso da Linguagem LOGO na cidade de São Paulo. A escola possuía por volta de 250 alunos distribuídos em cursos regulares de E. Infantil ao Ensino Médio.

Os alunos participantes responderam a um questionário sobre hábitos culturais cujo objetivo era fornecer informações sobre hábitos de leitura e de uso de computador. Os dados e comentários a seguir são fruto da observação efetuada durante a execução do projeto e da análise das informações coletadas por meio do questionário.

\footnotetext{
${ }^{7}$ Segundo o site da Logo Systems Inc., “ Micromundos é o Logo mais avançado que existe. Esse ambiente de aprendizagem único dá aos alunos simples, porém poderosos comandos e ferramentas para eles criarem projetos de excelente qualidade em qualquer matéria do currículo escolar. E, como o Micromundos trabalha com todos os tipos de mídia digital (vídeo, imagens, sons, botões, etc.) como objetos com nomes simples, é mais fácil de aprender e usar. O Micromundos não limita os alunos aos projetos ao estilo apresentação multimídia. Seu projeto de ferramenta aberta construtivista assegura que a criação de projetos baseados no computador não é um "cortar e colar" de mídia digital, mas um rigoroso exercício de pensamento.” Acesso em 20.05.2008, in: http://www.microworlds.com/por/company/profile.html
} 
Os dados obtidos por meio do questionário revelaram que as famílias cultivavam hábitos que possivelmente despertavam nas crianças o interesse pela leitura. Vários jovens mencionaram que eram presenteados com livros por pais e familiares e que tinham o hábito de ir a livrarias para escolher e comprar livros. Todos os alunos provinham de lares em que pelo menos um dos progenitores possuía curso superior (geralmente o pai). Como informação adicional, deve-se considerar ainda a temática dos livros indicados para leitura pela escola para ambas as séries: textos clássicos da literatura universal ambientados em épocas passadas (desde Odisséia até Robinson Crusoé).

Com exceção de uma aluna de $6^{\text {a }}$ série, nova na escola, todos os alunos participantes já haviam trabalhado com Logo e Micromundos em séries anteriores e não houve problemas no que se refere ao conhecimento dos procedimentos próprios desse programa.

Durante a pesquisa de campo, não se notou problema de relacionamento entre os alunos; predominou um clima de cooperação e de entendimento. Possivelmente, além dos fatores que serão comentados no item 3.2, essa situação pode ser atribuída a duas razões. A primeira delas refere-se ao costume que os alunos possuíam de trabalhar juntos, pois, como as turmas regulares eram pequenas, algumas atividades na escola eram feitas em conjunto pelas duas séries. Além disso, os alunos sabiam que o trabalho que realizariam não reverteria em nota; portanto, eliminou-se esse aspecto indesejável da competição. Os alunos, no entanto, tinham bastante grande em desenvolver um bom trabalho que seria apresentado aos pais e colegas no futuro Congresso do Conhecimento, uma espécie de feira cultural da escola em que todas as séries apresentavam trabalhos desenvolvidos durante o ano letivo.

\subsection{PROCEDIMENTOS ADOTADOS}

Ao apresentarmos nossa proposta de trabalho, solicitamos aos alunos que elaborassem narrativas ${ }^{8}$ que fizessem uso das diversas possibilidades de criação que um processador de textos e de imagens pode oferecer. Incluindo-se a característica de se mudar de página de acordo com uma seqüência previamente estudada pelo criador da história, ou seja, chamamos a atenção dos alunos para a sequenciação não-linear das páginas; eles poderiam, portanto, pré-

\footnotetext{
${ }^{8}$ As sete histórias (jogos) elaboradas receberam os seguintes títulos: A Mina de Ferro, O Castelo Possuído, O Tesouro de Atlântida, O Enigma das Cartas, Fúria de Príncipes, RPGF, O Castelo dos Fantasmas
} 
determinar a progressão de seus leitores através de "portas virtuais". Como se sabe, todo leitor bem estimulado quer avançar na narrativa, por isso enfatizou-se a questão da conquista do leitor através de uma narrativa atraente.

Solicitou-se também que o aluno desse especial atenção ao texto verbal. Os alunos foram incentivados a usar figuras, desenhos cenários criados por eles e não apenas aqueles “prontos” que se encontravam no programa.

\section{RESULTADOS E DISCUSSÃO}

Todos os alunos começaram a elaborar seus textos no primeiro encontro, muitos deles escreveram, então, toda a parte referente à introdução e construíram o cenário da primeira página. Um dos alunos, na segunda aula, esboçou em uma folha de papel o esquema completo do desenvolvimento da sua história.

Durante a realização da pesquisa de campo, constataram-se efeitos proveitosos que algumas atividades desenvolvidas no laboratório de informática apresentam. O principal deles refere-se à possibilidade de comunicação entre os alunos; normalmente um aluno procurava mostrar ao outro como estava conseguindo construir um cenário ou uma passagem de uma página a outra. Essa comunicação facilitava sobremaneira o trabalho da pesquisadora, pois lhe permitia acompanhar mais detalhadamente o processo de construção textual dos alunos.

O interesse dos alunos pelos trabalhos e pelo meio em que o mesmo se desenvolveu pode ser exemplificado pelo fato de que eles trabalhavam de maneira quase ininterrupta durante a hora e meia em que ficávamos no laboratório. Em média, durante toda a pesquisa, cada aluno faltou somente uma vez à aula (é preciso lembrar que o projeto desenvolvido não tinha nenhum vínculo curricular com outra disciplina).

Tais constatações corroboraram o que Schofield (1995) observou em suas pesquisas sobre o uso de computador em escolas, sobretudo no que diz respeito ao ambiente de troca de informações e experiências que se instaura entre alunos e entre alunos e professor.

Acreditamos que as características interativas dos textos do corpus não se devem apenas ao meio em que foram construídos; devem-se também a características específicas dos textos verbais, principalmente, narrativos que estiveram, estão e estarão presentes em nossas 
vidas. Buscando compreender como alunos de $5^{\mathrm{a}}$. e $6^{\mathrm{a}}$. empregam estratégias narrativas em textos interativos criados com o auxílio de um processador de textos e de imagens, definiu-se a perspectiva de análise sobre o emprego de três elementos essenciais para a estrutura do texto narrativo: narrador, personagem e enredo.

Neste relato, deteremos nossa atenção sobre narrador, pois acreditamos que esse elemento forneça dados suficientes para que possamos delimitar um modus operandi individual que pode nos revelar características próprias dos indivíduos do universo pesquisado. Embora, no presente texto, não discutamos em profundidade todos os elementos estudados, consideramos importante mencionar que nossa análise levou em conta não só a linguagem verbal do texto, mas também a utilização da linguagem não-verbal - figuras, animação das figuras e personagens - e a questão da duração temporal das ações, pois, por se tratar de um trabalho realizado com um processador de textos e imagens, nele ocorre, diversas vezes, o aparecimento e/ou desaparecimento de ações das personagens e das próprias personagens durante um determinado lapso de tempo.

$\mathrm{Na}$ tessitura do texto, os elementos da narrativa encontram-se imbricados ${ }^{9}$ e, de acordo com a abordagem teórica adotada neste trabalho, sua constituição e emprego revelamse como estratégias textuais (ou narrativas) adotadas em função dos efeitos que o autor busca produzir em seu leitor. Assim, nas narrativas, essas estratégias definem-se por meio de mecanismos que o autor emprega ao construir seu texto e que envolvem em maior ou menor grau todos os elementos da narrativa (narrador, personagem, enredo, espaço, tempo). A escolha de determinadas formas de discurso em detrimento de outras se configura como uma estratégia de negociação de significados e é por meio dessa estratégia que se torna possível compreender como se dá o processo de produção textual, pois, segundo Eco (1986, p.39), "gerar um texto significa executar uma estratégia de que fazem parte as previsões dos movimentos de outros - como, aliás, em qualquer estratégia.”. Assim, os processos envolvidos na criação de textos narrativos revestem-se de profundo interesse tanto para os campos da pesquisa literária e lingüística quanto para os estudiosos da cognição.

\footnotetext{
${ }^{9}$ A esse respeito julgamos interessante lembrar as palavras de Antonio Cãndido, in: A personagem de ficção, p. 54: “(... ) quando pensamos no enredo, pensamos simultaneamente nas personagens, quando pensamos nestas, pensamos simultaneamente na vida que vivem, nos problemas em que se enredam, na linha do seu destino traçada conforme uma certa duração temporal, referida determinadas condições de ambiente. O enredo existe através das personagens; as personagens vivem no enredo. Enredo e personagem exprimem, ligados, os intuitos do romance, a vida que decorre dele, os significados e valores que o animam.“
} 
O emprego de determinada estratégia textual envolve considerações e reflexões por parte do autor - ainda que este não se dê conta disso - que começam já na escolha do gênero, pois, ao optar por um gênero em especial, ele deverá adaptar seu enunciado aos cânones do gênero escolhido para que o mesmo corresponda a uma espécie de expectativa ficcional cujos limites são as fronteiras conhecidas e esperadas do gênero escolhido. De acordo com Todorov (1980, p.49), os "gêneros existem e funcionam como instituição e funcionam como 'horizontes de expectativa' para os leitores, como 'modelos de escritura' para os autores”. Essa dupla função dos gêneros faz com que os autores escrevam de acordo com o do sistema genérico existente e o que os leitores leiam conforme o "(...) sistema genérico que conhecem pela crítica, pela escola, pelo sistema de difusão do livro ou simplesmente por ouvir dizer; no entanto, não é necessário que sejam conscientes desse sistema." (TODOROV, 1980, p.49)

Portanto, a adoção de uma estratégia textual envolve fatores individuais e culturais intrinsecamente relacionados ao contexto de produção e circulação do texto escrito. Assim, a análise da estratégia textual e, mais particularmente, da estratégia narrativa pode levar à compreensão dos processos que engendram o texto narrativo bem como à criação de hipóteses sobre as intenções do autor desse texto.

Entretanto, convém salientar que os elementos em análise aparecem nos textos ficcionais de maneira simultânea e inter-relacionada e que a separação dos mesmos, para efeitos de análise, tem o exclusivo objetivo de estabelecer as estratégias narrativas empregadas pelos alunos, constituindo-se, dessa forma, um procedimento metodológico.

\subsection{ESTRATÉGIAS NARRATIVAS EMPREGADAS PELO NARRADOR}

A primeira característica com relação ao narrador observada no corpus refere-se ao emprego quase generalizado do narrador de terceira pessoa (das sete narrativas do corpus somente uma apresenta narrador-personagem). Trata-se, portanto, de uma característica predominante.

Em razão do caráter interativo e lúdico das narrativas, o narrador de terceira pessoa geralmente se apresenta como alguém que guiará o leitor-jogador dentro da narrativa gozando de uma condição inquestionável de onisciência. Outras vezes, percebe-se, claramente, a 
subordinação que apresenta o leitor-jogador diante da onisciência do narrador, demonstrada pela capacidade deste último de comentar fatos que ocorrerão no futuro ou fazer o leitorjogador saber que quem detém o conhecimento da história é o narrador, pois ele conhece os caminhos pelos quais o leitor-jogador deverá passar: Mesmo na narrativa que emprega o foco narrativo de primeira pessoa, as antecipações em relação ao que vai ocorrer com o leitorjogador estão presentes. A ocorrência desses dois recursos de produção textual - o uso do foco narrativo de $3^{\text {a }}$. pessoa e as antecipações - configura-se como uma estratégia de condução da narrativa; principalmente as antecipações que servem para manter a tensão em torno de conflitos que se apresentarão ao leitor-jogador.

Ainda em decorrência de uma estratégia narrativa adotada no sentido de manter o leitor-jogador atento ao desenrolar da trama e do jogo, observa-se, em cinco dos sete textos analisados, que o narrador faz uso de palavras de encorajamento (ainda que de forma indireta) para que o leitor-jogador continue a jogar mesmo quando sofre um revés em seu caminho. Essa estratégia aparece geralmente aliada a um questionamento direto que busca desafiar a coragem ou a esperteza do leitor-jogador. Pode-se verificar o uso associado ou dissociado dessa estratégia nos exemplos a seguir:

(...) .você bravamente matou o monstro." ou "Você foi muito bravo e morreu com honra nas chamas do terrível monstro.". (A Mina de Ferro $^{10}$

"Sabiamente você escolheu fugir da ameaça do disco-voador. Mas não ficará livre dos perigos. (RPGF)

Porém, nem sempre o narrador se apresenta tão polido com relação aos "erros” do leitor-jogador e, nesses momentos, lança mão de ironias, advertências, chacotas, juízos de valor (negativo):

"Vejo que você começa a usar seus neurônios. Clique no botão abaixo e preste mais atenção ao que está escrito." (O Enigma das Cartas)

Observam-se, nos exemplos acima, duas intencionalidades aparentemente contraditórias presentes nos discursos do narrador com relação ao tratamento dispensado ao leitor-jogador: o reforço positivo (através de palavras de encorajamento) e a crítica (e até

\footnotetext{
${ }^{10}$ Os nomes entre parênteses são os títulos atribuídos pelos alunos às suas produções.
} 
mesmo a chacota). São aparentemente contraditórias, pois, se analisadas de maneira contextualizada, elas revelarão extrema coerência: é preciso ter em mente que as histórias criadas são jogos em que, por princípio, deve haver um vencedor e um vencido.

Bakhtin (2002, p.135) afirma que "toda enunciação compreende antes de mais nada uma orientação apreciativa. É por isso que, na enunciação viva, cada elemento contém ao mesmo tempo um sentido e uma apreciação.”. Portanto, pode-se compreender o emprego dessa estratégia textual dentro de um quadro marcado pela intencionalidade do autor do discurso em dar significação a seus atos de linguagem. Atos esses que se constituem plenamente na medida em que os interlocutores reconhecem “saberes supostos” que se apresentam como condições mínimas de inteligibilidade para o discurso tecido entre ambos. ${ }^{11}$

Essa intencionalidade pressupõe também a orientação da palavra de acordo com os valores e dos interlocutores e é regida pelo princípio da interação verbal:

\begin{abstract}
"Essa orientação da palavra em função do interlocutor tem uma importância muito grande. Na realidade, toda palavra comporta duas faces. Ela é determinada tanto pelo fato de que procede de alguém, como pelo fato de que se dirige para alguém. Ela constitui justamente o produto da interação do locutor e do ouvinte. Toda palavra serve de expressão a um em relação ao outro. Através da palavra, definome em relação ao outro, isto é, em última análise, em relação à coletividade.” (BAKHTIN, 2002, p.113 - grifos do autor)
\end{abstract}

Segundo Bakhtin (2002), toda palavra, entendida aqui em sua dimensão discursiva, demanda uma resposta, uma contrapalavra ${ }^{12}$ (BAKHTIN, 2002). Ou seja, o processo de comunicação verbal, e mais estritamente o processo de construção de sentidos, coloca em jogo não apenas a capacidade de o ser humano expressar-se por meio da fala referida aqui em seu sentido estrito -, mas também, e principalmente, de se fazer entender e compreender o mundo por meio de todo um saber discursivo tecido pelas relações sociais de sujeitos constituídos social e historicamente. É dentro dessa compreensão que reside o princípio da responsividade que caracteriza o pensamento dialógico bakhtiniano.

\footnotetext{
${ }^{11}$ Patrick Charaudeu, Linguagem e discurso ..., p. 44, oferece uma definição de ato de linguagem que vai ao encontro das afirmações de Bakhtin: “ (...) vimos que o ato de linguagem como evento de produção ou de interpretação depende "dos saberes supostos que circulam entre os protagonistas da linguagem”. Estes saberes são correlativos à dupla dimensão Explícito/Implícito do fenômeno linguageiro.”

${ }^{12}$ Segundo M. Bakhtin, Marxismo e filosofia ..., p. 132, "A compreensão é uma forma de diálogo; ela está para enunciação assim como uma réplica está para a outra no diálogo. Compreender é opor à palavra do locutor a contrapalavra.
} 
"Compreender a enunciação de outrem significa orientar-se em relação a ela, encontrar o seu lugar adequado no contexto correspondente. A cada palavra da enunciação que estamos em processo de compreender, fazemos corresponder uma série de palavras nossas, formando uma réplica.” (BAKHTIN 2002, p.132)

O conceito de dialogia ocupa lugar central na teoria da linguagem desenvolvida por Bakhtin. Como vimos, todo enunciado prevê uma resposta, espera-a, antecipa-a, muitas vezes, modela-a. Das situações mais complexas às menos complexas, sempre esperamos uma resposta de nosso interlocutor. Além disso, nós mesmos, como seres construídos por meio de enunciados, de discursos, temos nossos próprios enunciados perpassados pelos discursos alheios. Nosso discurso é constituído por fragmentos de outros discursos, que negamos, ratificamos, transformamos, mas que jamais nos são indiferentes. Apropriamo-nos dos discursos de outros, fazemos confrontações; buscamos nosso próprio discurso entre os discursos alheios; enfim, constituímo-nos como seres de linguagem pela alteridade, pela responsividade, pela dialogicidade que marca todo e qualquer enunciado, seja ele pronunciado durante o diálogo face a face, seja ele composto pelas palavras escritas nos livros.

Nos textos em análise, o narrador deixa claro quem realmente está no comando. É ele quem dita e controla as regras do jogo. Configura-se assim uma situação de enunciação em que o narrador se coloca em posição de superioridade em relação a seu interlocutor. Charaudeau (2008, p.82), analisando os componentes da construção enunciativa, afirma que esta se dá quando: “O sujeito falante enuncia sua posição em relação ao interlocutor no momento em que, com o seu dizer, implica e lhe impõe um comportamento. Assim, o locutor age sobre o interlocutor (ponto de vista acional).” (grifos do autor). Dessa maneira, o narrador procura circunscrever as possíveis respostas do leitor-jogador dentro de um processo de construção enunciativa em que atribui, segundo Charaudeau (2008, p.82), "papéis linguageiros” a si e ao interlocutor.

Esses papéis são de dois tipos e evidenciam-se pela assunção de uma posição de superioridade ou de inferioridade do sujeito falante frente a seu interlocutor. "Essa imposição do locutor sobre o interlocutor estabelece entre ambos uma relação de força.” (CHARAUDEAU 2008, p.82 - grifos do autor). Em posição de inferioridade, o sujeito falante “assume papéis nos quais necessita do "saber” e do "poder fazer” do interlocutor. Produz-se uma solicitação do locutor ao interlocutor, o que estabelece entre ambos uma relação de petição (CHARAUDEAU 2008, p.82 - grifos do autor). 
No caso das histórias do corpus, constatou-se que em todas elas o narrador assume uma posição de superioridade em relação ao leitor-jogador, pois atribui "a si papéis que impõem ao interlocutor a execução de uma ação (“fazer fazer”/“fazer dizer”).” (CHARAUDEAU 2008, p.82 - grifos do autor). Trata-se, portanto, de uma relação de força que se manifesta claramente por meio dos discursos dos narradores. Entretanto, essa relação de força assume uma característica discursiva interessante, pois, se, por um lado, o narrador impõe regras e comportamentos a seus leitores-jogadores, por outro, procura desafiar seus brios. Essa estratégia revela-se, então, coerente com o gênero discursivo característico dos jogos que procuram cativar seus leitores-jogadores e, ao mesmo tempo, desafiar sua inteligência e habilidade. Porém, esse desafio não pode jamais se configurar como ordem sem permitir ao jogador a escolha de jogar ou não, pois, afinal, o jogo se caracteriza pela constante possibilidade de o jogador poder parar de jogar quando quiser. ${ }^{13}$

Outro fator, que desempenha um papel importante no caso das narrativas em análise, refere-se à possibilidade de, mesmo após ter cometido um erro que tenha levado o herói à morte, o leitor-jogador poder voltar ao início ou a uma página anterior e recomeçar o caminho. Portanto, trata-se de uma estratégia interessante do ponto de vista de controlar as reações do leitor-jogador, sobretudo quando se leva em conta que os alunos participantes do projeto sabiam que suas histórias seriam “jogadas” por seus colegas de escola. Nada mais instigante para um adolescente do que colocar em questão a capacidade intelectual de seu opositor; porém, isso deveria ser feito de uma forma que não levasse o leitor-jogador a se sentir muito inferiorizado e o desencorajasse de continuar o jogo, daí a necessidade das palavras de encorajamento. Portanto, criticar e desafiar a inteligência de seus oponentes (leitoresjogadores) sim, mas sempre com o cuidado de não exagerar na dose a fim de não perder sua “audiência”.

\footnotetext{
${ }^{13}$ Gilles Brougère, Jogo e Educação,p. 191, seguindo orientação já apresentada por Johan Huizinga na obra Homo Ludens, enfatiza a aprendizagem cultural do jogo e apresenta-a como uma aquisição baseada na linguagem: "O jogo não é um comportamento específico, mas uma situação na qual esse comportamento adquire uma significação específica. Vê-se em quê o jogo supões comunicação e interpretação. Para que essa situação em particular se crie, há uma decisão por parte dos jogadores: decisão de entrar no jogo, mas também de organizá-lo de acordo com modalidades particulares. Sem livre escolha, isto é, possibilidade real de decidir, não há mais jogo, e sim sucessão de comportamentos que têm sua origem fora do jogador.”
} 
Pode-se encontrar na preocupação de empregar uma estratégia que torne a narrativa e o jogo dela decorrente um “ambiente” agradável e ao mesmo tempo desafiador ao leitorjogador a explicação para o uso de um narrador de terceira pessoa que procura aproximar-se do leitor-jogador, apresentando-se como seu companheiro de aventuras e desventuras.

Numa síntese das estratégias empregadas pelo narrador, observamos que em todas as histórias do corpus o narrador não deixa dúvidas: é ele quem conduz o leitor-jogador dentro da trama e ocupa, por isso, uma posição de superioridade. O caráter autoritário do narrador é reforçado pelo modo verbal, o imperativo, com que ele se dirige ao leitor-jogador para que este proceda de acordo com o que ele previu. As ordens são claras: procure, clique, escolha, etc. Como vimos, outra forma de buscar a adesão do leitor-jogador para que ele aja de acordo com as previsões do narrador refere-se ao uso de expressões de encorajamento, de crítica e até mesmo de chacota, que devem ser vistas como extremamente pertinentes quando analisadas de forma contextualizada considerando-se o gênero discursivo “jogo de video game” Além de contar com essas formas diretas de encorajamento e crítica, por vezes o narrador lança mão de maneiras indiretas para reforçar ou criticar uma atitude tomada pelo leitor-jogador ou faz uso de sua capacidade de prever o futuro do herói (e do leitor-jogador).

Não é de se estranhar, portanto, o emprego majoritário nas narrativas do discurso indireto, uma vez que esse tipo de discurso permite ao narrador um maior controle da situação narrada na medida em que a fala, o pensamento e as ações das personagens são filtrados por sua voz.

É, portanto, por meio das estratégias acima mencionadas que o narrador consegue “fechar” o leitor-jogador dentro dos limites ficcionais que ele criou. Certamente, esse conjunto de estratégias revela-se bastante adequado, pois procura motivar o leitor-jogador a continuar o jogo e fazer com que aja de acordo com o que foi previsto pelo narrador. Trata-se, assim, de estratégias de elaboração de toda uma trama em que o leitor-jogador deve inserir-se de maneira cooperativa, o que vai ao encontro das palavras de Eco (1986, p.39):

“(...) o texto postula a cooperação do leitor condição própria de atualização. Podemos dizer melhor que o texto é um produto cujo destino interpretativo deve fazer parte do próprio mecanismo gerativo. Gerar um texto significa executar estratégias de que fazem parte as previsões dos movimentos dos outros como, aliás, em qualquer estratégia.” (grifos do autor) 
Dentro dessa perspectiva de análise, o leitor-jogador concreto a quem se dirige o narrador torna-se, usando-se a terminologia de Eco, o leitor-modelo, entidade ideal em função da qual se organiza a estratégia textual e cuja interpretação o narrador quer direcionar. Portanto, não se podem considerar obras do acaso as semelhanças nas formas encontradas nos textos do corpus de o narrador buscar cooperação do leitor; pelo contrário, essa preocupação revela-se como uma estratégia engendrada com a intenção específica de causar no leitorjogador sentimentos capazes de gerar ações (“fazer fazer”) de acordo com as intenções do narrador demonstrando assim o conhecimento do gênero e dos discursos a ele pertinentes. Trata-se, assim, de guiar o leitor-jogador (leitor-modelo) somente pelos caminhos previstos e desejados pelo narrador, pois segundo Eco (1986, p.40): “prever o próprio Leitor-Modelo não significa somente "esperar" que exista, mas significa também mover o texto de modo a construí-lo”.

Porém, a análise do narrador não se esgota aqui, é preciso atentar para o fato de que nos textos do corpus, o narrador não apenas conta a história, mas também dá instruções operacionais (que dizem respeito a procedimentos que devem ser tomados pelo leitor-jogador) para que as narrativas possam ter continuidade. Tais instruções, na maioria das vezes, resumem-se a ordens (descubra, escolha, clique), porém, em algumas ocasiões, referem-se a procedimentos mais complicados como, por exemplo, fechar e abrir um arquivo ou perguntar ao leitor-jogador se ele já “passou” por determinada situação para que possa prosseguir na trama.

Nesses dois casos, o narrador conta principalmente com a colaboração do leitorjogador para que este dê continuidade à história tal qual ela foi concebida, pois nada impede, em termos operacionais, que o leitor-jogador pule etapas dos jogos. Pode-se inferir, por meio dessa atitude do narrador, que ele considera que seu leitor-jogador estará empenhado em descobrir o final da história e que este não lançará mão de truques ou trapaças. Demonstrandose assim de maneira clara que o narrador acredita que seu interlocutor jogará o jogo de acordo com as regras propostas. O narrador conta, claramente, com uma atitude responsiva do leitorjogador baseada numa espécie de pacto contratual e ético que rege os jogos: o de não trapacear.

Todas essas considerações apontam para processos de construção de textos (ou de estratégias narrativas) efetuados por um narrador cioso de suas “obrigações” de manter o interesse e provocar determinadas ações de seu leitor. Diante do acima exposto, observa-se a 
intenção clara que os alunos produtores das narrativas têm de adaptar seus discursos às regras de construção e de conduta que regem a maioria dos jogos. Adequando-os, portanto, ao discurso do gênero em que consideram se inserir suas narrativas.

Bakhtin (1992, p.300), ao estudar os gêneros do discurso, tratou da questão da adaptação do enunciado ao gênero do discurso ligando-a a uma intenção definida pelo autor que molda "o tema em função de uma dada abordagem do problema, do material, dos objetivos a atingir”. Dessa forma,

\begin{abstract}
"sentimos o intuito discursivo ou o querer-dizer do locutor que determina o todo do enunciado: sua amplitude, suas fronteiras. Percebemos o que o locutor quer dizer e é em comparação a esse intuito discursivo a esse querer-dizer (como o tivermos captado) que mediremos o acabamento do enunciado.” (grifos do autor) (BAKHTIN 1992, p.300)
\end{abstract}

Antes de terminarmos o estudo do narrador, é preciso que se façam algumas observações referentes ao aspecto cognitivo verificadas durante o experimento.

Do ponto de vista constitutivo da situação de comunicação ${ }^{14}$ proposta pelo experimento aqui relatado, nota-se que ela se insere num quadro um pouco mais complexo do ponto de vista cognitivo que a elaboração de narrativas “tradicionais”, uma vez que os textos analisados contêm etapas que não são linearmente construídas e que são extremamente moventes. As telas se abrem e se fecham de acordo com as opções feitas pelo leitor-jogador, surgem elementos “mágicos” ou não - armas, pedras, amuletos - o próprio texto que acompanha o objeto pode aparecer e/ou desaparecer depois de algum tempo.

A mobilidade e fugacidade das situações demandam do narrador (autor) um domínio completo de todos os desdobramentos da trama, pois não se pode deixar o leitorjogador "passar" duas vezes pelo mesmo caminho e ele também não pode "se cansar" dos desafios, que devem ser novos e instigantes a cada etapa. Trata-se, portanto, de uma arquitetura movente em que o desenvolvimento cognitivo do aluno se apresenta de maneira evidente para o pesquisador. Qual a progressão lógica da história? Como induzir o leitor-jogador a fazer determinadas escolhas durante a história? Esses foram alguns dos desafios vencidos pelos alunos participantes do experimento conforme a análise do narrador demonstrou.

\footnotetext{
${ }^{14}$ Segundo Patrick Charaudeau \& Dominique Maingueneau, Dicionário de análise de discurso, p. 450, a situação de comunicação não se opõe a “contexto”, esse termo refere-se ao conjunto de condições que organizam a emissão de um ato de linguagem.”
} 


\subsection{AMBIENTE DE APRENDIZAGEM}

O aspecto mais importante no que se refere ao trabalho desenvolvido no laboratório de informática, a nosso ver, diz respeito a mudanças de atitude do aluno, do professor e do relacionamento destes com o conhecimento propriamente dito.

A primeira constatação de mudança de atitude do aluno está relacionada diretamente com a própria transformação do papel do professor dentro do laboratório de informática que, muitas vezes, pode ser notada até mesmo pela disposição espacial dos alunos e do professor dentro do laboratório. Diferentemente da sala de aula em que normalmente a mesa do professor fica à frente da classe, o que o coloca numa posição de destaque, no laboratório em que desenvolvemos nosso trabalho não havia mesa ou cadeira do professor. Sentávamos lado a lado com os alunos e dispúnhamos, em princípio, dos mesmos materiais para o trabalho. Quando um aluno sentia alguma dificuldade, chamava-nos e discutíamos (e tentávamos) soluções; se não dessem certo, solicitávamos que outros alunos nos ajudassem. Às vezes, nem era preciso chamá-los, eles se aproximavam espontaneamente e faziam sugestões, ensinavam procedimentos técnicos, discutiam estratégias. Encontramos nesse processo condições semelhantes às que Vygotsky definiu como Zona de Desenvolvimento Proximal, ou seja, a distância entre o nível de desenvolvimento real, em que a criança consegue resolver problemas de maneira independente, e o nível de desenvolvimento potencial, em que ela consegue resolver o problema com a ajuda de um adulto ou de um colega mais capaz. Nesse sentido, Vygotsky (1991, p.101) destaca que:

\footnotetext{
“(...) um aspecto essencial do aprendizado é o fato de ele criar a zona de desenvolvimento proximal; ou seja, o aprendizado desperta vários processos internos de desenvolvimento, que são capazes de operar somente quando a criança interage com pessoas em seu ambiente e quando em cooperação com seus companheiros. Uma vez internalizados, esses processos tornam-se parte das aquisições do desenvolvimento independente da criança."
}

Transformações também ocorreram quanto ao assunto das conversas dos alunos no laboratório de informática. Como em toda sala de aula, havia conversas, porém, geralmente, estavam relacionadas com a tarefa que se desenvolvia. As conversas paralelas ocupavam pouquíssimo tempo do aluno. Acreditamos que um dos fatores para que isso acontecesse é o fato de o computador ser uma ferramenta interativa por natureza. Quando executamos um procedimento, ficamos atentos para ver se o mesmo ocorreu como queríamos, para, em 
seguida, darmos prosseguimento à tarefa; não é necessário esperar que o professor a corrija. $\mathrm{O}$ próprio aluno avalia e constata a adequação ou não de seus procedimentos (respostas) a determinada situação.

Outra peculiaridade do trabalho realizado no laboratório de informática é o caráter "público" de que se reveste a tarefa. Em nossas sessões, dificilmente um aluno deixava de ver o que o outro estava escrevendo ou desenhando, porque podia observar a distância o que aparecia na tela do computador ou porque era chamado pelo colega. A facilidade de visualização também favorecia a intervenção da pesquisadora. Esses fatores conjugados permitem o deslocamento, por parte do aluno, do foco de atenção para o próprio processo de construção do conhecimento. Dado um objetivo, o aluno deverá descobrir meios de atingi-lo com as ferramentas de que dispõe. É claro que esse tipo de trabalho pode ser feito em qualquer sala de aula, porém, no laboratório de informática ele pode se tornar mais dinâmico e atraente para o aluno.

Além do fator “computador” como elemento motivador do aluno, também era favorável à realização do projeto a sedução exercida pelos jogos de computador sobre os jovens. A proposta de trabalho contemplava a possibilidade de os alunos criarem seus próprios jogos para colegas jogarem. A idéia de tornar públicas suas produções fascinava muitos alunos. Dispúnhamos, portanto, de fatores estimulantes em nossa atividade de criação textual. Indicadores do interesse despertado nos alunos podem ser encontrados na sua assiduidade e nas várias vezes em que o horário de término previsto para os encontros semanais foi ultrapassado.

\subsection{ESTRATÉGIAS NARRATIVAS E COGNIÇÃO}

Apesar da motivação acima mencionada, constatamos que alguns alunos tiveram dificuldades em estruturar o texto coerentemente. Acreditamos que tais dificuldades foram motivadas pela arquitetura de um texto com características hipertextuais. É importante frisar que todos os alunos deveriam jogar seus jogos antes de considerá-los “terminados”. Todos os alunos jogaram todos os jogos para verificar se ”faltava” alguma página ou passagem. Esse procedimento não evitou, porém, que ocorressem dois casos em que alguns desenvolvimentos de enredo não continham páginas que lhes dessem continuidade. Os dois casos aconteceram com alunos da $5^{\mathrm{a}}$ série que tentaram entrecruzar as páginas dos enredos. Por meio desse 
procedimento, os alunos pretendiam usar uma mesma página para enredos diferentes (ou seja, essa página deveria ser acessada por comandos presentes em diversas outras páginas e, ao mesmo tempo, permitir que se passasse a diversas outras páginas). O emprego dessa técnica acabou se revelando desastroso para a maioria dos alunos, pois dos quatro que a usaram somente um conseguiu fazê-lo de forma adequada.

Nesse caso, consideramos que os alunos possuíam condições de planejar uma determinada ação com um determinado instrumento, mas não tinham ainda condições efetivas de realizar a empreitada sozinhos. Na tentativa de compreender o porquê dessa situação, valemo-nos dos experimentos realizados por Vygotsky (1991). Estudando a questão do uso de instrumentos pela criança, Vygotsky enfatiza que muitas vezes ela consegue planejar suas ações, mas não tem condições reais de implementá-las ${ }^{15}$. Acreditamos que os alunos tinham um planejamento de como realizariam seus trabalhos, porém nem todos conseguiram efetivamente realizá-lo, pois não se encontravam num estágio de desenvolvimento cognitivo que lhes permitisse controlar todas as variáveis contidas nos jogos (textos). É a explicação encontrada para o fato de, entre os alunos que “esqueceram” uma ou mais páginas, estar um aluno que, numa folha de papel, elaborou espontaneamente, no segundo dia de aula, um esquema por ele usado em quase todas as sessões contendo praticamente todas as etapas do jogo que iria desenvolver.

Apesar desses problemas de continuidade narrativa, todas as narrativas apresentaram a solução da busca do herói. Nenhuma história deixou de apresentar, pelo menos em uma das “portas virtuais”, exposição, desenvolvimento e desenlace completos.

Ainda na questão referente à adaptação do texto ao meio eletrônico, observamos que três alunos empregaram recursos de animação, porém dois deles não informaram ao leitor-jogador essa possibilidade. Do nosso ponto de vista, esse aviso fazia-se necessário, pois quando abríamos uma página do jogo todo o cenário permanecia estático a menos que clicássemos sobre determinado elemento. Quando questionados sobre o motivo pelo qual eles não haviam mencionado no texto verbal a existência da animação, obtivemos duas respostas.

\footnotetext{
${ }^{15}$ VYGOTSKY, in: A formação social da mente, p. 33, afirma: "Em resumo, quando as crianças se confrontam com um problema um pouco mais complicado para elas, apresentam uma variedade complexa de respostas que incluem: tentativas diretas de atingir o objetivo, uso de instrumentos, fala dirigida à pessoa que conduz 0 experimento ou fala que simplesmente acompanha a ação e apelos verbais diretos ao objeto de sua atenção."
} 
Um deles disse que cabia ao leitor-jogador descobrir essa possibilidade e que se este descobrisse sozinho provaria ser bom conhecedor de Micromundos. Portanto, o aluno havia criado o jogo para um público específico e havia colocado a questão da animação como mais um desafio a ser vencido no jogo. Outro aluno afirmou que quando se abre um jogo de video game ou de computador não é preciso ser informado de que há recursos de animação.

Essas duas respostas permitem compreender que os alunos conceberam os jogos como linguagem em movimento diferentemente da maneira com que nós, adultos, os analisamos. Mesmo lidando razoavelmente bem com computador e com jogos de video game e de computador, fomos alfabetizados culturalmente, num sentido bastante amplo, num mundo caracterizado pela ordem linear e pelo espaço limitado da folha de papel e até mesmo da tela de televisão ou de cinema, enquanto muitas crianças já estão sendo alfabetizadas com hipertextos que incorporam uma multiplicidade de recursos manipulados por elas próprias. Portanto, é imprescindível ter-se em mente que os padrões de compreensão do mundo estão, como sempre estiveram, em constante transformação, porém, nunca na história da Humanidade as transformações ocorreram com tamanha velocidade como hoje. Babin \& Koloumdjian (1989, p.173-174) tratam com bastante propriedade a questão das mudanças que estão ocorrendo nos modos de compreensão desde a chegada de recursos audiovisuais e de computador na sociedade, fazendo uma analogia entre o funcionamento em estéreo e em mono de um equipamento de som e o modo de compreender do ser humano afirmam:

Funcionar em estéreo é instaurar duas vias, dois modos de compreensão e expressão. Às vezes, é o registro artístico, global, intuitivo, “gustativo" que domina. Outras, é o registro analítico rigoroso, seqüencial, abstrato. E há passagem de um a outro, mas respeitando os pontos de vista e predominâncias.

Esses autores ainda resumem: "Fala-se com a imagem ao invés de falar da imagem.” (BABIN; KOULOUMDJIAN 1989, p.173 - grifos nossos)

Portanto, devemos estar atentos para o fato de que os seres humanos operam e compreendem o mundo por intermédio de valores, ferramentas e instrumentos culturalmente elaborados (entre eles os textos orais e escritos) e de que são, por sua vez, de maneira dialógica $^{16}$, transformados por eles.

\footnotetext{
${ }^{16}$ A respeito do caráter dialógico do enunciado Baktin (in: Estética da Criação Verbal 1992, p.317) afirma: "Por mais monológico que seja um enunciado (...), por mais que se concentre sobre o mesmo objeto, sobre o mesmo problema, ainda que esse caráter de resposta não receba uma expressão externa bem perceptível. A resposta transparecerá nas tonalidades do sentido, da expressividade, do estilo, nos mais ínfimos matizes da composição. As tonalidades dialógicas preenchem um enunciado e devemos levá-las em conta se quisermos
} 


\title{
4. CONSIDERAÇÕES FINAIS
}

\begin{abstract}
“(...) aprender a usar a linguagem envolve ao mesmo tempo aprender a cultura e aprender como expressar as intenções em congruência com a cultura. Isso nos traz a questão de como podemos conceber "cultura" e de que maneira ela fornece meios não apenas para transacionar com os outros, mas para nos concebermos em tais transações." Bruner (1998, p.69)
\end{abstract}

Por meio da análise das estratégias narrativas empregadas pelos narradores, verificamos que foram usados procedimentos de elaboração textual que visavam a conseguir uma atitude cooperativa do leitor: inserindo-o na história, “jogando” com ele, elogiando-o, desafiando-o. Também foi constatado o uso coerente do foco narrativo e do discurso indireto nas narrativas do corpus. Outras estratégias proporcionaram ao texto a adequação ao gênero ficcional que foi solicitado aos alunos. A adequação apresentou-se pela criação de estratégias de narração (ponto de vista, digressões, intrusões, flash-backs). Os alunos aplicaram, na maioria das vezes, essas técnicas de maneira bastante adequada com o objetivo de conseguir a adesão do leitor e de, ao mesmo tempo, circunscrevê-lo aos limites ficcionais da narrativa.

O emprego adequado dessas estratégias revela que os alunos não só empregam coerentemente os procedimentos enunciativos como também dominam o gênero textual a que pertence a narrativa recheada de desafios em que se busca mais que a compreensão da história, busca-se também a habilidade de jogar com informações que se modificam, que se movem e ganham nova roupagem dependendo do desenvolvimento da trama da história que se impõe de maneira fragmentada e inesperada.

Houve também adaptação de técnicas e procedimentos próprios do software Micromundos às peculiaridades do trabalho proposto aos alunos (o desenho de figuras e cenários, o emprego de páginas interligando dois ou mais desenvolvimentos de enredos, recursos de animação). A aplicação desses procedimentos e técnicas buscava, como observamos, conseguir não só uma atitude cooperativa dos leitores mas também tornar as histórias tecnicamente atraentes. A atitude cooperativa do leitor-jogador foi solicitada por meio do emprego de estratégias que uniam o uso de modos verbais, linguagem sedutora e

compreender até o fim o estilo do enunciado. Pois nosso próprio pensamento - nos âmbitos da filosofia, das ciências, das artes - nasce e forma-se em interação e em luta com o pensamento alheio, o que não pode deixar de refletir nas formas de expressão verbal do nosso pensamento." 
desafiadora, personagens envolvidas em lutas entre o bem e o mal, objetos e seres mágicos e, principalmente, o desafio natural que a idéia de jogo encerra. Assim, num processo dialógico, as narrativas do corpus constroem, adaptam e discutem realidades ficcionais transformadas pela percepção literária e cultural de quem as engendrou.

\section{REFERÊNCIAS}

ADAM, J. - Le récit. Paris: Presses Universitaires de France, 1994. (Coleção Que sais-je?).

BABIN, P.; KOULOUMDJIAN, M.-F. Os novos modos de compreender. São Paulo: Paulinas, 1989.

BAKHTIN, M. Estética da Criação Verbal. São Paulo: Martins Fontes, 1992. . (VOLOCHINOV). Marxismo e filosofia da linguagem. São Paulo: Hucitec, 2002.

BORGES, J. L. El jardin de senderos que se bifurcan. In: Ficciones. Buenos Aires: Emecé Ed., 1993.

BRITTON, B. K.; PELLEGRINI, A D.(Org.). Narrative Thought and Narrative Language. New Jersey: Lawrence Erlbaum Associates, Publishers, 1990

BROUGÈRE, G. Jogo e educação. Porto Alegre: Artes Médicas, 1998.

BRUNER, J. A cultura da educação. Porto Alegre: Artes Médicas, 2001.

Atos de significação. Porto Alegre: Artes Médicas, 1997.

Realidades mentais, mundos possíveis. Porto Alegre: Artes Médicas, 1998.

CALVINO, I. Seis propostas para o próximo milênio. São Paulo: Cia. das Letras, 1990.

CÂNDIDO, A. et al. A personagem de ficção. São Paulo: Perspectiva, 1995.

CHAFE, W. Some things that narratives tell us about the mind. In: BRITTON, B.; PELLEGRINI, A. D. (Orgs.) Narrative Thought and Narrative Language. New Jersey: Lawrence Erlbaum Associates, Publishers, 1990

CHARAUDEAU, P.;MAINGUENEAU, D. Dicionário de análise do discurso. São Paulo: Contexto, 2004.

Linguagem e discurso: modos de organização. São Paulo: Contexto, 2008. 
ECO, U. Lector in Fabula. São Paulo: Perspectiva, 1986.

. Seis Passeios pelos Bosques da Ficção. São Paulo: Cia. das Letras, 1997.

LÜDKE, M.; ANDRÉ, M. E. D. A. Pesquisa em Educação: Abordagens Qualitativas. São Paulo: E..P.U., 1986.

MUNGIOLI, M. C. P. Apontamentos para o estudo da narrativa. Comunicação e Educação, São Paulo, n. 23, jan./abr. 2002. p. 49-56.

Narrativas e computador: criando mundos e experimentando realidades. Educação:

Teoria e Prática, Rio Claro, SP, n. 25, v. 13, jul./dez. 2005, p. 65-78.

Narrativas e computador: diálogos entre mundos reais e mundos possíveis. 2000.

165 p. Dissertação (Mestrado em Educação) - Faculdade de Educação da Universidade de São Paulo. São Paulo, 2000.

OLSON, D. R.; TORRANCE, N. (Org.). Cultura Escrita e Oralidade. São Paulo: Ática, 1995.

. Thinking about narrative. In: BRITTON, B.; PELLEGRINI, A. D. (Orgs.).

Narrative Thought and Narrative Language. New Jersey: Lawrence Erlbaum Associates, Publishers, 1990.

SCHOFIELD, J. W. Computers and classroom culture. New York: Cambridge University Press, 1995.

TODOROV, T. Os gêneros do discurso. São Paulo: Martins Fontes, 1980.

VYGOTSKY, L. S. A formação social da mente. São Paulo: Martins Fontes, 1991. 
MARIA CRISTINA PALMA MUNGIOLI

Professora da Escola de Comunicações e Artes da Universidade de São

Paulo.

Doutora em Ciências da Comunicação pela ECA-USP.

E-mail: cristinapalmamungioli@gmail.com

Recebido em: 03/08/2008

Publicado em: 31/01/2009 